\title{
Noninvasive biomarkers predict improvement in liver fibrosis after successful generic DAAs based therapy of chronic hepatitis C in Egypt
}

\author{
Ekram W. Abd El-Wahab (MBChB, MPH, PhD) ${ }^{\mathrm{a}, 1, *}$, \\ Hesham AK. Ayoub (MBChB, MA, MD, PhD) ${ }^{\text {b,c,d }}$, Aziza A. Shorbila (MBChB, DPH, MPH) ${ }^{\mathrm{e}}$, \\ Ashraf Mikheal (MBChB, MA, MD, PhD) ${ }^{f}$, Mohamed Fadl (MBChB, MA, MD, PhD) ${ }^{f}$, \\ Amira M. Kotkat (MBChB, MPH, Dr.PH) ${ }^{a}$
}

${ }^{a}$ Department of Tropical Health, High Institute of Public Health, Alexandria University, Egypt

${ }^{\mathrm{b}}$ Department of Hepatology and Endemic Medicine, Military Medical Academy, Cairo, Egypt

${ }^{\mathrm{c}}$ Director of the Viral Hepatitis Unit, Qappary Hospital, Ministry of Health and Population, Alexandra, Egypt

${ }^{\mathrm{d}}$ Chief consultant of Hepatology Department, Qappary Hospital, Ministry of Health and Population, Alexandra, Egypt

${ }^{\mathrm{e}}$ Fellow of Tropical Health Department, High Institute of Public Health, Alexandria University, Egypt

${ }^{\mathrm{f}}$ Consultant of Hepatogastroentrology and Endemic Diseases, Damanhour Fever Hospital, Ministry of Health and Population, Egypt

\section{A R T I C L E I N F O}

\section{Keywords:}

DAAs

Liver fibrosis

Improvement

HCV genotype 4

Egypt

\begin{abstract}
A B S T R A C T
Background: The scale of HCV problem in Egypt prioritized the development of a national control strategy that employs the use of locally manufactured generic direct-acting antivirals (DAAs). Achieving sustained virologic response in chronic HCV patients is the key for preventing fibrosis progression and ultimately its resolution. Objective(s): To evaluate impact of generic DAAs on liver fibrosis in chronic HCV patients using some noninvasive biomarkers (NIBMs).

Methods: A total of 280 chronic HCV patients (18 treatment experienced and 262 naive) were enrolled and received the standard of care. All patients were clinically evaluated before starting treatment and at 4, 12 and 24 weeks of treatment.

Results: The sensitivity and the specificity of the tested NIBMs for predicting cirrhosis versus liver ultrasound ranged between $75.0-79.6 \%$ and 59.4-67.2\% respectively. All NIBMs showed significant linear decline during the treatment and follow up periods among responders but tended to fluctuate in values toward an increase among non-responders. In cox regression analysis, normal baseline ALT, AST, total serum cholesterol, serum albumin, WBCS, prothrombin activity and early stages of liver fibrosis predicted improvement in liver fibrosis by $1.5-2$ folds. The mean probability of recovery at $1,3,6$ months varied between the different scores and ranged from 0.059 to $0.637,0.125-0.741,0.538-0.951$ respectively.

Conclusion: The results provide prognostic data on the improvement in liver fibrosis over the treatment course and follow up periods without the need for a liver biopsy. Early detection and management of HCV infection should be emphasized to maximize the benefits of the treatment.
\end{abstract}

\section{Introduction}

Chronic hepatitis $\mathrm{C}$ (CHC) is a leading cause of advanced liver disease and associated mortality. Successful antiviral therapy with sustained virological response (SVR) can reduce liver-related morbidity and mortality as well as the need for transplantation. ${ }^{1-3}$ Assessment of the stage of liver fibrosis is important for diagnosis, treatment, and follow-up both during and after completion of the treatment. Non- invasive methods for assessing the degree of fibrosis are currently substituting liver biopsy owing to its inherit risk of complications. ${ }^{4-6}$ Among the non-invasive modalities, transient elastography (TE; FibroScan ${ }^{\circledast}$ ) is the most accurate in assessing liver stiffness. ${ }^{7,8}$ However, this non-invasive method is expensive and is not widely available particularly in poor resource countries. ${ }^{8}$

Recently many noninvasive biomarkers (NIBMs) for assessing liver fibrosis have been developed, and are frequently used in clinical

\footnotetext{
* Corresponding author. Tropical Health Department High Institute of Public Health 165 El-Horreya Road, 21561, Alexandria, Egypt.

E-mail address: ekram.wassim@alexu.edu.eg (E.W. Abd El-Wahab).

${ }^{1}$ To whom Correspondence should be addressed.
} 
practice. They have been validated in different studies, and some were found to be highly accurate in the assessment of liver fibrosis comparing to liver biopsies ${ }^{9}$; which have always been used as the standard reference for evaluating the accuracy of noninvasive methods. The NIBMs are ideal in assessing the stage of fibrosis in patients with $\mathrm{CHC}$ or chronic hepatitis $B$ and who require longitudinal evaluation of the stage of fibrosis after achieving the SVR. ${ }^{8-12}$

NIBMs for liver fibrosis comprise direct biomarkers (class 1) and indirect biomarkers (class 2). The direct markers are produced by the hepatic stellate cells and correlate with extracellular matrix turnover in fibrosis process. On the other hand, the indirect markers including the AST/ALT Ratio (AAR), AST to Platelet Ratio Index (APRI), Forns index, FIB-4 score, Lok index, cirrhosis discrimination score (CDS) and Göteborg University Cirrhosis Index (GUCI) reflect changes in liver

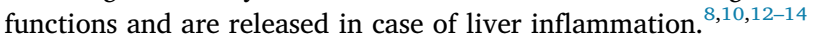

Together with the suppression of HCV replication, response to antiviral therapy with interferon or ribavirin reduces liver complications in $\mathrm{CHC}^{15,16}$ with sufficient evidence of improvement in liver histology. ${ }^{17,18}$ However, little is known about the evolution of liver fibrosis in HCV patients in the new era of directly acting antivirals (DAAs) that revolutionized HCV treatment with cure rates exceeding $95 \%$ regardless the infecting genotype.$^{19}$ In this study, we proceeded to evaluate post-treatment improvement in liver fibrosis in chronic HCV patients using some NIBMs in settings where TE is not available.

\section{Methods}

\subsection{Study design and patients}

A prospective real-life cohort study [one group pre-test post-test design] was conducted between July 2016 and October 2017 at some Liver Center in Alexandria and El-Behira governorates. These centers are affiliated to the Ministry of Health and Population in Egypt and provide the standard of care of $\mathrm{CHC}$ according to the international guidelines. $^{20,21}$

A minimal sample of $35 \mathrm{HCV}$ patients with hepatic fibrosis was required to estimate an average reduction of $50 \%$ at fibrosis rate after having HCV treatment protocol. ${ }^{18}$ The employed equation used an alpha error $=0.05$ and intervention effect size $=0.5$ with an expected drop out rate $=10 \%$ that will provide a study power of $80 \%$. The sample size was calculated using G. power software.

The sample size was increased to compensate for the drop out during the follow-up. The sample units were consecutively selected after fulfilling inclusion criteria. The study patients comprised chronic HCV positive patients (naïve and -experienced) eligible for receiving DAAs. In total, 18 (6.4\%) patients were experienced for INF and RBV regimens. The patients are referred to the center for receiving DAAs as standard care. The criteria for inclusion were: ages above 18 years, both sex, HCV-RNA positive PCR, HBsAg seronegative, complete blood picture within normal ranges and all eligible cases for treatment according to international guidelines (Child A, Child B). ${ }^{21,22}$ Those found ineligible for the treatment were excluded from the study [Age under 18, HBV seropositive, history of malignancy, untreated thyroid disease, active substance abuse, and hepatic decompensation [(Child $\mathrm{C}$ ), (Albumin $<2.8 \mathrm{~g} / \mathrm{dl}$, TSB $>3 \mathrm{mg} / \mathrm{dl}$, international normalized ratio (INR) $>1.3$, platelets $<50000 / \mathrm{cmm}$ ) , presence of ascites on Ultra sound, uncontrolled diabetes (HbA1C $>9 \%$ ), current or planned pregnancy, end stage renal disease or serum creatinine greater than $1.5 \mathrm{mg}$ / $\mathrm{ml}$, continued pattern of alcohol abuse $>40 \mathrm{~g} /$ day in the last 6 month, WBC $<3000 / \mathrm{cmm}$, Hemoglobin $<10 \mathrm{~g} / \mathrm{dl}$, hepatocellular carcinoma (HCC), retinopathy, HIV, and obese patients (Body Mass Index (BMI) $>35)]$. $^{21,22}$

\subsection{Clinical and laboratory investigations}

All enrolled patients were interviewed using structured predesigned questionnaire to collect sociodemographic data, history of previous treatment for HCV and were subjected to complete medical examination (general and abdominal) including the estimation of the BMI and any features of decompensated cirrhosis. Baseline laboratory investigations for proper selection of eligible cases for treatment comprised: complete Blood Count (CBC), fasting blood glucose, liver function tests, total serum bilirubin (TSB), alanine Aminotransferase (ALT), aspartate Aminotransferase (AST), total serum cholesterol (TSC), serum gamma-glutamyl transferase ( $\mathrm{\gamma GT}$ ), prothrombin time, prothrombin activity (PA), international normalized ratio (INR), serum albumin, serum creatinine, anti-nuclear antibody (ANA), thyroid stimulating hormone (TSH), free T3, free T4, alpha fetoprotein (AFP), antibilharzial $\mathrm{Ab}, \mathrm{HIV} \mathrm{Ab}, \mathrm{HBsAg}$ and $\mathrm{HBcAb}$ as markers for HBV infection [Enzymelinked immunosorbent assay (3rd generation ELISA kit DIALAB ${ }^{\circledR}$, Austria), HCV RNA quantitation by Real-Time PCR using Cobas Ampli Prep/Cobas TaqMan HCV-RNA assay (Roche Diagnostics; Pleasanton, CA, USA) with a threshold of detection $=15 \mathrm{IU} / \mathrm{ml}$, anti-bilharzial Ab: [indirect hemagglutination test (IHA) (Fumouze Diagnostics, France)]. Pregnancy test was done for women in child bearing age. ECG and fundus examination were done for all patients. Those found seropositive for bilharziasis received antibilharzial treatment regimen for 10 days prior to enrollment in the HCV treatment cohort.

All patients underwent abdominal ultrasound examination to check for the general condition of the liver and other abdominal organs. Liver fibrosis or cirrhosis was evaluated by ultrasound and was inferred from the calculated liver fibrosis scores namely; AAR ratio, APRI score, Forns index, FIB-4 score, lok index, and GUCI. ${ }^{8,23}$

\subsection{Medications and regimens of combination therapy}

The anti-HCV drugs used in the current study were supplied by local manufacturers in Egypt and their effectiveness and safety were found comparable to brand drugs. ${ }^{24,25}$

Since genotype 4 is predominating in Egypt, ${ }^{26-29}$ all enrolled patients received Sofosbuvir/Daclatasvir combination therapy; i) Patients with chronic hepatitis without cirrhosis were given SOF + DAC for 12 weeks, ii) patients with cirrhosis or relapsers after pegyinterferon/ribavirin combination therapy were given SOF + DAC + RBV for 12 weeks. The combination therapy was given as: Sofosbuvir $400 \mathrm{mg}$ PO qDay, Daclatasvir 60 mg PO qDay, Ribavirin (Rebetol; Schering-Plough $\mathrm{K} \cdot \mathrm{K}$. ), was given in two divided daily oral doses adjusted to body weight (800 mg for weights $<50 \mathrm{~kg}, 1,000 \mathrm{mg}$ for weights $50-65 \mathrm{~kg}, 1,200 \mathrm{mg}$ for weight $65-80 \mathrm{~kg}$, and 1,400 $\mathrm{mg}$ for weights $>80 \mathrm{~kg}$ ).

To compensate for $\mathrm{Hb}$ drop caused by Ribavirin, folic acid and iron supplements were given to patients. All patients found positive for Antishistosomal Ab received praziquantal $60 \mathrm{mg} / \mathrm{kg} /$ day orally in 3 divided doses for 10 day before starting DAAs.

\subsection{Follow up}

Patients underwent follow up during the 12 weeks of treatment period and for 12 weeks after treatment. At week 4, 12 of treatment and at weeks 12 post-treatment all enrolled patients were subjected laboratory investigations, including $\mathrm{CBC}$, liver function and renal function tests as well as qRT-PCR for viral load to detect early (EVR) and sustained virologic responses (SVR12).

\subsection{Treatment endpoints}

EVR was defined as undetectable HCV-RNA or below the lower limit of quantification at 4 weeks of initiation of treatment, while the SVR12 was defined as undetectable HCV-RNA or below the lower limit of quantification at 12 weeks after the last dose of treatment (or at 24 week of starting treatment) as endpoint.

The primary efficacy endpoint was achieving an SVR at 12 weeks after the end of therapy (EOT) defined as HCV-RNA below the assay's 
lower limit of detection (LLOD). Secondary efficacy endpoints included EOT virological response, defined as HCV-RNA below the assay's LLOD measured at the EOT. Null-responder was defined as HCV RNA persistently high not reaching < LLOD throughout the treatment period, or HCV-RNA $\geq$ LLOD at EOT. Relapse was defined as confirmed HCV RNA > LLOD during any post-treatment follow-up visit in patients with HCV-RNA < LLOD at the EOT.

\subsection{Statistical analysis}

Data were collected, revised for accuracy and completeness, coded and fed to statistical software SPSS (Statistical Package for the Social Sciences) version 21.0 (IBM ${ }^{\otimes}$ Corp., Armonk, NY, USA). The results were statistically analyzed, tabulated and displayed in appropriate figures and tables. All statistical analysis was done using two tailed tests and alpha error of 0.05 . Significance of the obtained results was judged at the $5 \%$ level $(p \leq 0.05)$. Numbers, percent, means with standard deviation and the median were used to describe the scale and categorical data, respectively. Pearson's Chi-square test, Mont Carlo exact test and Fishers exact test were used to test for the association between the categories of two independent samples. The mean \pm SD of the calculated scores were calculated at $0,4,12$, and 24 weeks and their performance was compared between responders and non-responders. Repeated measures ANOVA was used to test the differences in means of quantitative variables measured at different time points. Cox regression analysis (or proportional hazards regression) was used to investigating the effect of several variables upon the time a specified event takes to happen; thus to determine the factors associated post treatment improvement in liver fibrosis over the course of treatment and follow up periods. Recovered defined improvement in liver fibrosis based on NIBMs scores and censored defined lack of improvement. In this context, FIB-4 was used a liver fibrosis scoring model. The model included all host related variables [Age, gender, occupation, residence, co-morbidities, past history of INF therapy] as well as the different hematological, biochemical and virologic parameters. Receiver operator characteristic curve (ROC curve) was used to assess the diagnostic accuracies of noninvasive indices for predicting cirrhosis versus liver ultrasound. Kaplan Meir test was used to assess post treatment regression in liver fibrosis using some non-invasive biomarkers. In Kaplan Meier analysis, recovery (improvement in liver fibrosis scores) was used as the event-of-interest. Seven liver fibrosis biomarker scores were tested and their performance was compared.

Extrapolation forecasting equation was used to predict the continuous progressive regression in liver fibrosis. The latter employed the use of a linear equation to predict the probability of improvement in liver fibrosis beyond our data sets.

\section{Results}

\subsection{Socio-demographics of the enrolled HCV patients}

We enrolled a total of 280 chronic HCV patients. The majority of the participants were rural residents (60.4\%) and in the age group 50-75 years $(66.1 \%)$ with an overall mean \pm SD of $52.0 \pm 10.3$ years. Males and females were equally presented $(50.7 \%$ vs $49.3 \%$ respectively). Other sociodemographics are detailed in (Table 1).

\subsection{Medical history and physical examination of the enrolled HCV patients}

Previous history of INF therapy was reported by $6.4 \%$ of the enrolled HCV patients under treatment. Almost one half $(53.5 \%)$ of chronic HCV patients were free of co-morbidities, while $30.0 \%$ were diabetic, $14.3 \%$ were hypertensive, $5.7 \%$ had renal diseases and $5.4 \%$ had portal hypertension (Fig. S1). The most frequently reported symptoms throughout the course of DAAs based therapy were fatigue (88.2\%), flu like symptoms (60.7\%), gastrointestinal upsets $(19.3 \%)$,
Table 1

Socio-demographic characteristics and personal habits of the enrolled HCV patients.

\begin{tabular}{|c|c|c|c|}
\hline \multirow[t]{2}{*}{ Characteristic } & & \multicolumn{2}{|c|}{ Total participants $(n=280)$} \\
\hline & & No. & $\%$ \\
\hline \multirow[t]{3}{*}{ Age } & $20-$ & 17 & 6.1 \\
\hline & $35-$ & 78 & 27.8 \\
\hline & $50-73$ & 185 & 66.1 \\
\hline \multirow[t]{2}{*}{ Gender } & Male & 142 & 50.7 \\
\hline & Female & 138 & 49.3 \\
\hline \multirow[t]{2}{*}{ Residence } & Urban & 111 & 39.6 \\
\hline & Rural & 169 & 60.4 \\
\hline \multirow[t]{4}{*}{ Marital status } & Single & 13 & 4.6 \\
\hline & Married & 230 & 82.1 \\
\hline & Widowed & 28 & 10.1 \\
\hline & Divorced & 9 & 3.2 \\
\hline \multirow[t]{6}{*}{ Education } & Illiterate & 12 & 4.3 \\
\hline & Read \& Write & 17 & 6.1 \\
\hline & Primary Education & 27 & 9.6 \\
\hline & Preparatory Education & 22 & 7.8 \\
\hline & Secondary Education & 129 & 46.1 \\
\hline & University Education & 73 & 26.1 \\
\hline \multirow{9}{*}{ Occupation } & Not Working & 32 & 11.4 \\
\hline & Farmer & 40 & 14.3 \\
\hline & Employee & 62 & 22.1 \\
\hline & Professional & 5 & 1.8 \\
\hline & HCW & 9 & 3.2 \\
\hline & Housewife & 82 & 29.3 \\
\hline & Clerk & 43 & 15.4 \\
\hline & Student & 3 & 1.1 \\
\hline & Others & 4 & 1.4 \\
\hline \multirow[t]{4}{*}{ BMI } & $<18$ underweight & 1 & 0.4 \\
\hline & 18- normal weight & 9 & 3.2 \\
\hline & 25- overweight & 69 & 24.6 \\
\hline & $30+$ overweight & 201 & 71.8 \\
\hline \multirow[t]{2}{*}{ Smoking } & Yes & 80 & 28.6 \\
\hline & No & 200 & 71.4 \\
\hline \multirow[t]{2}{*}{ Alcohol } & Yes & 0 & 0.0 \\
\hline & No & 280 & 100.0 \\
\hline \multirow[t]{2}{*}{ Drug abuse } & Yes & 1 & 0.4 \\
\hline & No & 279 & 99.6 \\
\hline
\end{tabular}

infections (13.2\%) and skin rash (6.8\%). Liver ultrasound of the enrolled HCV patient revealed liver cirrhosis (64.6\%), abnormal echo pattern $(25.2 \%)$, splenomegaly $(9.6 \%)$, fatty fibrosis $(8.9 \%)$ and coarse bright liver (6.1\%) (Fig. S2). Accordingly, the presence of cirrhosis or fibrosis among HCV patients under treatment was $77.1 \%$.

\subsection{Efficacy, safety and tolerability of the administered DAAs drug regimens}

The sustained virologic response rate among the HCV patients who received the standard DAA regimen was $98.6 \%$. By week four of treatment, $87.9 \%$ had cleared the virus and became HCV-RNA negative, thus achieved EVR. All but 2 patients maintained virologic suppression while receiving therapy and recorded an EOTSVR as a treatment endpoint (99.3\%). Thus, EOT virologic non response at week 12 was experienced by 2 patients $(0.7 \%)$. The latter maintained non response during follow up and another two patients relapsed at week 24 during follow up (Fig. 1).

All but one of the non-responders $(75.0 \%)$ were naïve and the response rate among treatment experienced patients was $94.4 \%$. All nonresponders $(100.0 \%$ ) were cirrhotics ( $>$ F3 on FIB-4), had significantly high TSB, AFP, INR, yGT levels and decreased platelet count and prothrombin activity thus were categorized as difficult to treat $(p<0.001)$.

In univariate logistic regression analysis, several factors were found significantly associated with non-response to HCV therapy (Table S1). SVR12 was not achieved in smokers [OR $(95 \% \mathrm{CI})=0.1(0.01-1.3)$, $p=0.04]$, elevated AFP [OR $(95 \%=1.1(1.01-1.2) p<0.001]$, decreased prothrombin activity [OR $(95 \% \mathrm{CI})=1.1(1.0-1.1) p=0.001]$, 


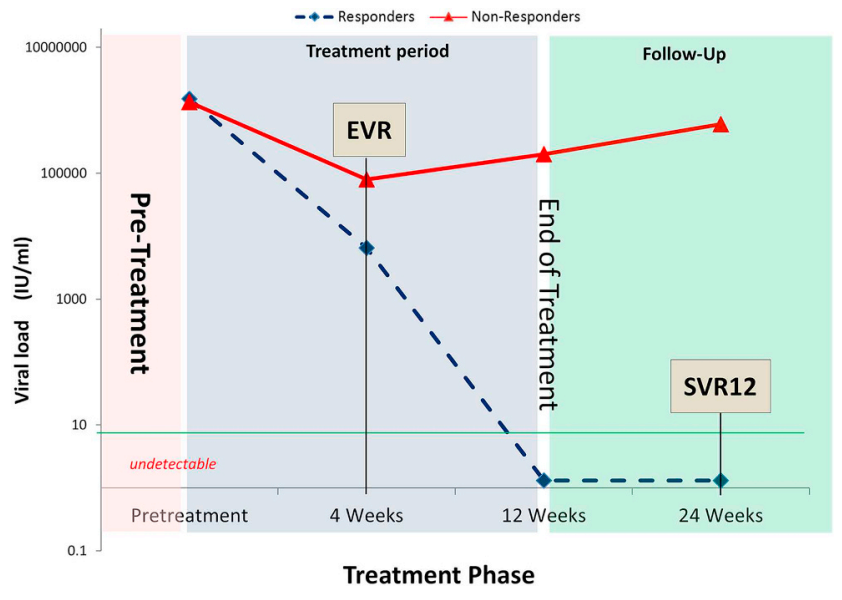

Fig. 1. Virologic response during treatment and follow-up periods.

higher than normal INR [OR $(95 \% \mathrm{CI})=1.1(1.0-1.2), p<0.001]$, higher than normal TSB [OR $(95 \% \mathrm{CI})=1.1(1.0-1.1) p=0.001]$, low platelet count $[\mathrm{OR}(95 \% \mathrm{CI})=1(1-1.1) p=0.023]$, higher than normal yGT [OR $(95 \% \mathrm{CI})=1.04(1.01-1.04) p=0.004]$, being difficult to treat $[\mathrm{OR}(95 \% \mathrm{CI})=1.1(1.0-1.3) p<0.001]$, having F3 fibrosis as determined by FIB-4 $[p=0.015]$. The means of all the calculated noninvasive liver fibrosis scores were significantly higher among nonresponders $[p=0.015]$. Nonetheless, none of these variables predicted non response in the multivariate logistic regression model.

\subsection{Hematological, biochemical and virological changes over the course of treatment}

There was a significant and linear improvement in all the laboratory findings over the treatment course and during the follow up periods among the responders comparing to non-responders as revealed by the repeated measures ANOVA test. In overall, the effect size attributed to the treatment response was significantly higher comparing to the effect of the time course (Table S2 and Fig. S3).

\subsection{Diagnostic accuracies of noninvasive indices for predicting cirrhosis versus liver ultrasound}

Fig. 2 illustrates the diagnostic accuracies of noninvasive indices for predicting cirrhosis versus liver ultrasound. The area under the ROC curve (AUROC) for the liver fibrosis score showed that the best performance was for FIB-4 (AUROC $=0.791 ; \mathrm{CI}=73.4 \%-84.8 \%$ ) followed by king's score (AUCROC $=0.786 ; \mathrm{CI}=72.7 \%-84.5 \%$ ), mFIB-4 (AUROC $=0.771 ; \mathrm{CI}=70.9 \%-83.8 \%)$, Forns index $($ AUROC $=0.771$; $\mathrm{CI}=71.1 \%-83.1 \%)$, GUCI (AUCROC $=0.766 ; \mathrm{CI}=70.5 \%-82.6 \%)$, Lok index (AUROC $=0.762 ; \quad \mathrm{CI}=69.9 \%-82.5 \%$ ), and APRI score (AUROC $=0.760 ; \mathrm{CI}=69.9 \%-82.1 \%$ ). On the other hand, the performance of AAR was not accurate in detecting the state of fibrosis (AUROC $=0.567 ; \mathrm{CI}=48.9 \%-65.4 \%$ ). The sensitivity and the specificity of the evaluated liver fibrosis scores ranged between 75.0-79.6\% and $59.4-67.2 \%$ respectively. Assuming that the ultrasound is a reliable and valid instrument for diagnosing liver fibrosis/cirrhosis, the interrater reliability as measured by Cohen's Kappa ( $\kappa$ ) test for all the calculated liver fibrosis scores in comparison to liver ultrasound was fair $(\kappa$ values ranged between 0.261 and 0.355 if excluding the AAR and the AARPRI ${ }^{30}$ for detecting liver fibrosis/cirrhosis $(p<0.001)$.

\subsection{Assessment of post treatment regression in liver fibrosis using some} NIBMs

Apart from the AAR, all non-invasive liver fibrosis scores showed significant linear decline during treatment and follow up periods among responders $(p<0.05)$. On the other hand, the majority of these scores tended to fluctuate in values toward an increase in a non-linear pattern among non-responders. In overall, the effect size in liver fibrosis scores attributed to the treatment response was significantly higher comparing to the effect of the time course. The largest effect size was demonstrated in a linear pattern by the King's score (20.5\%), GUCI (18.7\%), APRI $(13.1 \%)$, FIB-4 (9.0\%), and Forns index $(4.4 \%)(p<0.05)$ (Table 2 and Fig. 3).

\subsection{Factors associated with post treatment improvement in liver fibrosis}

In Cox regression analysis, normal ALT [OR 95\% CI $=1.7$ (1.14-2.5)], serum albumin [OR 95\% CI = $1.9(1.1-3.4)]$, WBCS [OR $95 \% \mathrm{CI}=1.12(1.02-1.2)]$, prothrombin activity $[\mathrm{OR} 95 \% \mathrm{CI}=1.5$ $(1.02-2.2)$ ] and F0-F1in FIB-4 liver fibrosis scoring [OR 95\% CI $=1.9$ (1.13-3.2)] predicted $1.5-2$ folds improvement in liver fibrosis $(p<0.05)$. The increase in AST, TSC, Forns index and CDS by one unit was associated with decreased probability for fibrosis regression by about $8 \%, 6 \%, 41.5 \%$ and $16.6 \%$ respectively $(p<0.05)$. On the other hand, the increase in yGT, King's and CDS by one unit increased the probability for fibrosis regression by about $7 \%$ and $9 \%$ respectively $(p<0.05)$ (Table 3).

\subsection{Prediction of continuous progressive regression in liver fibrosis overtime}

Kaplan Meier analysis revealed that the probability of recovery among the treatment non-responders was consistently zero as demonstrated by all the tested scores. The number of people who recovered among responders varied between the different scores and ranged from 100 to 183; being lowest for the Lok Index (100) and highest for the APRI and GUCI score (183). In total, 34 subjects did not recovery until the end of the study. The probability of recovery at 1, 3, 6 months varied between the different scores and ranged from 0.059 to 0.637 , 0.125-0.741, 0.538-0.951 respectively. APRI, FIB-4, GUCI and King's scores demonstrated statistically significant differences for the Log Rank, Breslow and Tarone-Ware tests of equality of recovery among responders and non-responders $(p<0.001)$ (Table 4 and Figs. $4-5)$.

The employed extrapolation forecasting test predicted continuous progressive regression in liver fibrosis (Fig. 6).

\section{Discussion}

In 2014, generic DAAs regimens were successfully introduced as a part of the national CHC treatment program in Egypt. Eligible patients receive the standard of care according to the approved treatment recommendations. ${ }^{21}$ SVR and improvement of liver fibrosis are ultimate goals for DAAs based therapy. ${ }^{31}$ Gradual resolution of liver fibrosis occurs after alleviating the necroinflammation and damage in sustained viral responders. However, this requires accurate and serial longterm evaluation. $^{31-35}$

A total of 280 chronic HCV patients were enrolled in the study. Their ages ranged between 20 and 73 as complying with eligibility criteria for treatment. However, the majority of the participants were in the age group 50-73 with an overall mean age of 52 years. This is consistent with the higher HCV infection rates among older population in Egypt. In fact HCV infected patient in this age group must have acquired HCV infection through blood transfusion before implementing the screening of blood and blood products in blood banks for blood borne viruses in 1992 or during the era of parenteral anti-schistosomal therapy. ${ }^{36}$ The latter was led in large-scale campaigns (between 1950s and 1980s) by the Egyptian Ministry of Health for controlling schistosomiasis and was the main driver of the HCV epidemic in Egypt. ${ }^{36}$

In accordance with El-Zanaty and co-workers ${ }^{37}$ most of the participants were from rural side where the prevalence is greatest for Schistosomiasis and HCV infection. Population characteristics were typical to those of rural communities in Egypt where farming is the 


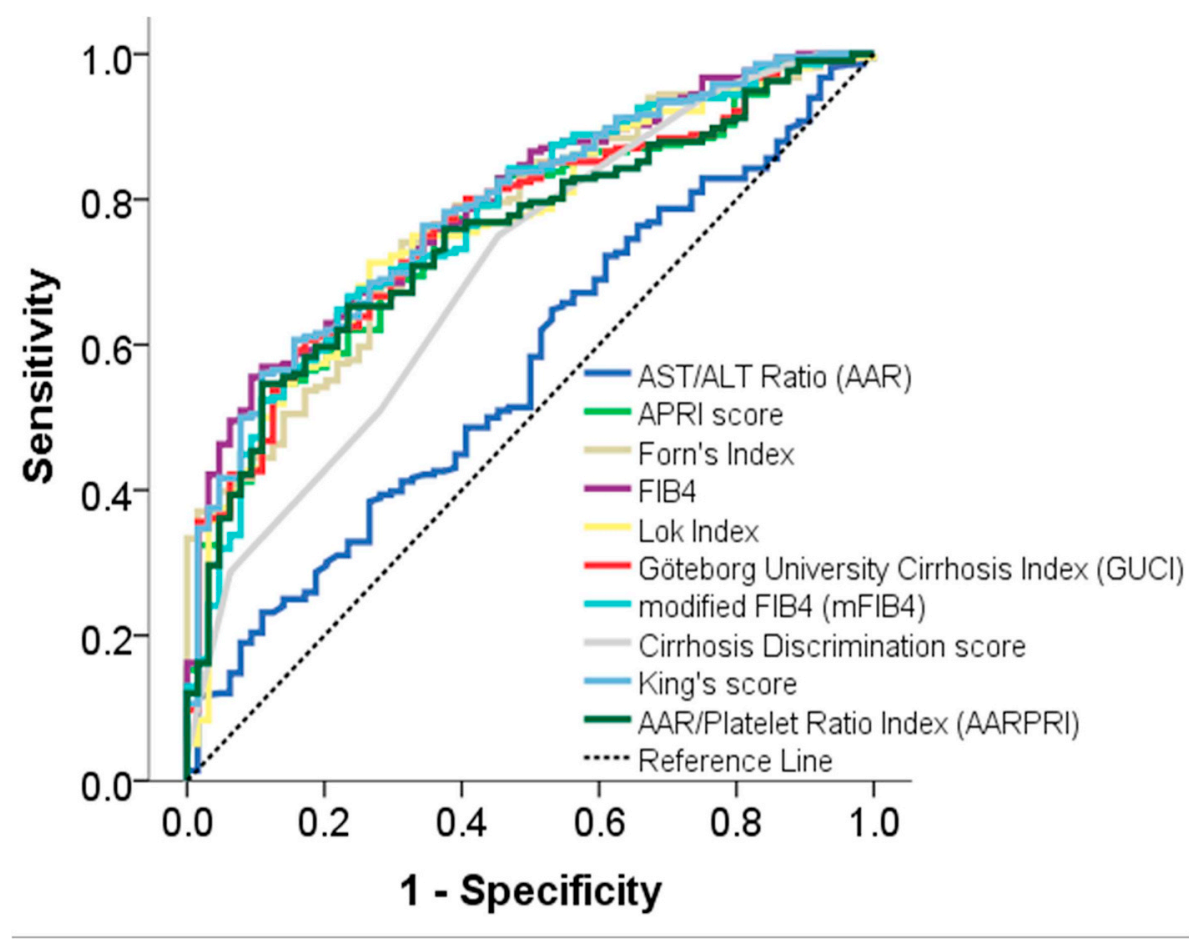

\begin{tabular}{|c|c|c|c|c|c|c|c|c|c|c|}
\hline \multicolumn{6}{|c|}{ Area Under the Curve } & \multirow{3}{*}{$\begin{array}{l}\text { Old } \\
\text { cut off } \\
\text { point }{ }^{\text {c }}\end{array}$} & \multirow{3}{*}{$\begin{array}{l}\text { New } \\
\text { cutoff } \\
\text { point }\end{array}$} & \multirow{3}{*}{ к } & \multirow{3}{*}{ 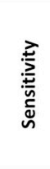 } & \multirow{3}{*}{ 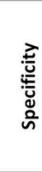 } \\
\hline \multirow[t]{2}{*}{ Test Result Variable(s) } & \multirow[t]{2}{*}{ Area } & \multirow{2}{*}{$\begin{array}{l}\text { Std. } \\
\text { Errora }\end{array}$} & \multirow{2}{*}{ 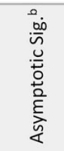 } & \multicolumn{2}{|c|}{$\begin{array}{l}\text { Asymptotic } 95 \% \\
\text { Confidence } \\
\text { Interval }\end{array}$} & & & & & \\
\hline & & & & $\begin{array}{l}\text { Lower } \\
\text { Bound }\end{array}$ & $\begin{array}{l}\text { Upper } \\
\text { Bound }\end{array}$ & & & & & \\
\hline AST/ALT Ratio & 0.567 & 0.040 & 0.103 & 0.489 & 0.645 & 1.0 & - & 0.030 & - & - \\
\hline APRI score & 0.760 & 0.031 & 0.0 & 0.699 & 0.821 & 1.5 & 0.5 & 0.328 & 75.0 & 64.1 \\
\hline Forn's index & 0.771 & 0.031 & 0.0 & 0.711 & 0.831 & 6.9 & 5.05 & 0.336 & 79.2 & 60.9 \\
\hline FIB4 & 0.791 & 0.029 & 0.0 & 0.734 & 0.848 & 1.45 & 1.48 & 0.343 & 78.7 & 59.4 \\
\hline Göteborg University Cirrhosis Index (GUCI) & 0.766 & 0.031 & 0.0 & 0.705 & 0.826 & 0.26 & 0.5 & 0.355 & 79.6 & 59.4 \\
\hline mFIB4 & 0.771 & 0.032 & 0.0 & 0.709 & 0.834 & 4.0 & 2.35 & 0.314 & 76.4 & 59.4 \\
\hline Lok Index & 0.762 & 0.032 & 0.0 & 0.699 & 0.825 & 0.5 & 0.4 & 0.344 & 79.6 & 59.4 \\
\hline Cirrhosis Discrimination score (CDS) & 0.701 & 0.037 & 0.0 & 0.629 & 0.774 & 3.0 & 4.5 & 0.261 & 75.0 & 54.7 \\
\hline King score & 0.786 & 0.030 & 0.0 & 0.727 & 0.845 & 11.8 & 10.1 & 0.343 & 79.2 & 59.4 \\
\hline AARPRI & 0.749 & 0.032 & 0.0 & 0.686 & 0.811 & 1.0 & 0.75 & 0.125 & 75.9 & 62.5 \\
\hline
\end{tabular}

Fig. 2. AUROC summary of performance characteristics of tested noninvasive biomarkers for the diagnosis of cirrhosis among the enrolled HCV patients.

principal occupation and illiteracy is prevailing. ${ }^{36,37}$

Almost one half were free of co-morbidities. The most frequently reported chronic diseases were DM, hypertension and renal disease and portal hypertension. In fact, these chronic diseases are prevailing in the general population worldwide and in Egypt. ${ }^{37,38}$ Moreover, the majority $(78.5 \%)$ of those having co-morbidities were in the age group 50-75 years $(p<0.001)$.

Based on liver ultrasound, the majority of the enrolled HCV patient had some degrees of liver fibrosis or cirrhosis. In fact, most of liver disease centers in Egypt relay on liver ultrasound for providing diagnostic and prognostic information as well as detecting complications such as HCC and portal hypertension. However, it does not provide sufficient clues for diagnosing liver fibrosis and is only sensitive in $60 \%$ of the cases. ${ }^{39,40}$ So, patients in the present cohort with detected abnormal echo pattern or coarse bright liver may have a degree of fibrosis which cannot be judged by the conventional ultrasound. Moreover, it is difficult in some cases to differentiate liver fibrosis from fatty liver which is a common condition among the Egyptian population particularly HCV patients. ${ }^{41,42}$ Further, MR elastography (MRE) appears to be the most reliable method for grading liver fibrosis. ${ }^{43}$ TE and MRE have comparable accuracy for detecting significant fibrosis. ${ }^{44}$ However, these modalities are not used in Egypt for the evaluation of HCV patients before treatment or during their follow up.

In concordance with results from previous clinical trials and real life experiences, all but $4(1.4 \%)$ of the enrolled patient became HCV-RNA negative by 12 weeks of treatment with an overall response rate (SVR12) of $98.6 \%$ for the administered DAAs regimens. ${ }^{45,46}$ The treatment was well tolerated and none of the self-reported drug adverse reactions forced any of the study participants to discontinue the treatment course. ${ }^{45-48}$ Interestingly, all experienced patient but one achieved SVR despite that the majority (88.93\%) had cirrhosis but only $22.0 \%$ of them were classified as difficult to treat. This agrees with Nagaty et al., ${ }^{46}$ but contradict Elsharkawy et al. as they reported that treatment-naive patients had higher SVR rates than the treatment-experienced patients. ${ }^{49}$

Prediabetics are less likely to respond to treatment comparing to diabetics suggesting insulin resistance as main player. ${ }^{50,51}$ However, in the current real life cohort, all diabetics responded well to HCV therapy and all non-responders were non diabetics and had normal baseline FBS, PPBG as well as normal HbA1C. In fact, diabetics should have glycemic control under control of antidiabetic therapy that was found to improve the response to antiviral treatment. ${ }^{52}$ On the other hand, glucose abnormalities appear to have little impact on treatment response in DAAs treated patients. ${ }^{53,54}$ High insulin in insulin resistance may inhibit the ability of interferon $\alpha$ to block HCV replication due to the activation of PI3K by insulin, thus leading to inhibition of STAT-1, which is involved in the interferon $\alpha$ pathway. ${ }^{55}$ The impact of diabetes mellitus and insulin resistance on HCV infection and treatment response needs to be further evaluated with the new DAAs.

The overall performance of the liver fibrosis indices in predicting 


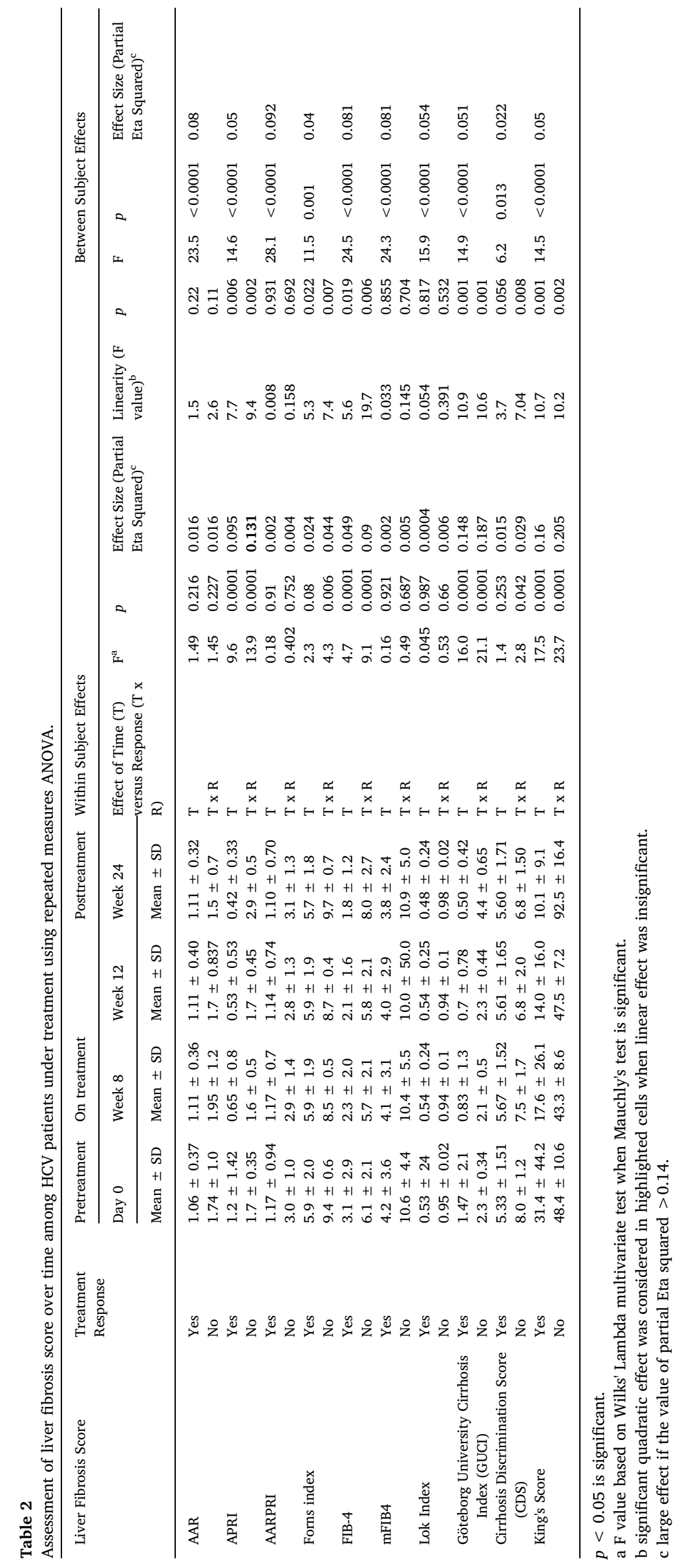



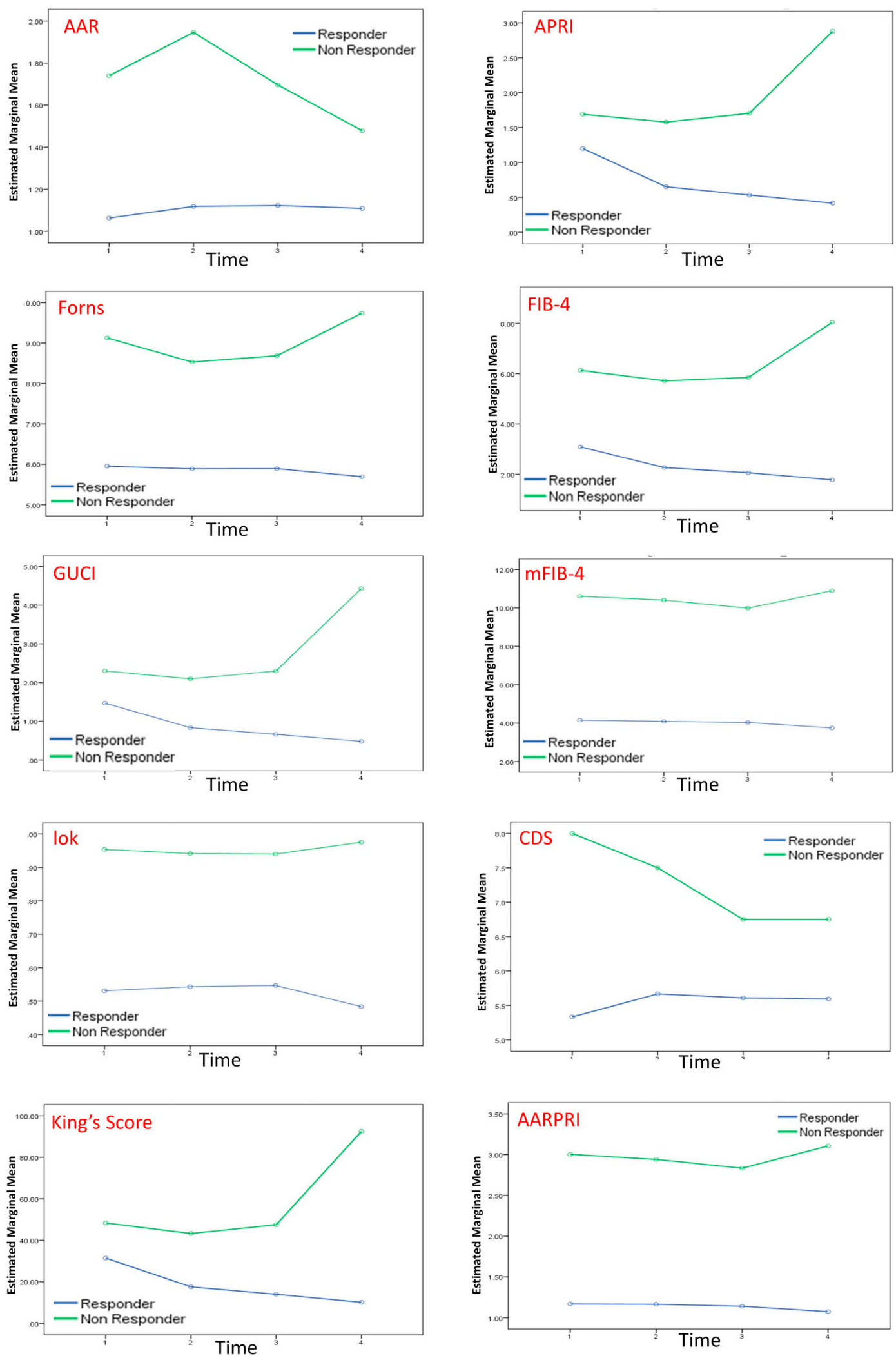

Fig. 3. Liver fibrosis score over time among HCV patients under treatment.

liver fibrosis/cirrhosis versus ultrasound was fair as the AUROC did not exceed 8 in any of the tested scores. Moreover, comparing the performance versus ultrasound as a gold standard is not a good choice owing to its suboptimal accuracy in detecting liver fibrosis ${ }^{39,40}$ and thus we got fair agreement between the two instruments in diagnosing liver fibrosis/cirrhosis. In fact, routine clinical ultrasound is not a sensitive predictor of early fibrosis in chronic viral hepatitis. Surface nodularity is the most sensitive sonographic feature for the detection of significant fibrosis and routine clinical ultrasound is the most useful for the detection of cirrhosis. This means that a significant number of patients 
Table 3

Cox regression [Backward Wald method] for factors affection the improvement in liver fibrosis.

\begin{tabular}{|c|c|c|c|c|c|c|c|c|c|}
\hline \multirow[t]{2}{*}{ Step 61} & \multirow[t]{2}{*}{ Variable } & \multirow[t]{2}{*}{ B } & \multirow[t]{2}{*}{ SE } & \multirow[t]{2}{*}{ Wald } & \multirow[t]{2}{*}{ df } & \multirow[t]{2}{*}{ Sig. $p$ value } & \multirow[t]{2}{*}{$\operatorname{Exp}(B)$} & \multicolumn{2}{|c|}{$95.0 \%$ CI for $\operatorname{Exp}(B)$} \\
\hline & & & & & & & & LB & UB \\
\hline & Normal ALT & .518 & .195 & 7.029 & 1 & .008 & 1.679 & 1.145 & 2.462 \\
\hline & Elevated AST & -.008 & .004 & 4.689 & 1 & .030 & .992 & .985 & .999 \\
\hline & Normal Albumin & .645 & .303 & 4.535 & 1 & .033 & 1.906 & 1.053 & 3.449 \\
\hline & Normal Prothrombin Activity & .397 & .194 & 4.203 & 1 & .040 & 1.488 & 1.018 & 2.175 \\
\hline & Normal WBCs & .116 & .045 & 6.725 & 1 & .010 & 1.123 & 1.029 & 1.227 \\
\hline & Elevated total serum cholesterol & -.006 & .003 & 5.175 & 1 & .023 & .994 & .988 & .999 \\
\hline & Elevated yGT & .007 & .003 & 5.473 & 1 & .019 & 1.007 & 1.001 & 1.012 \\
\hline & Forns Index & -.415 & .150 & 7.680 & 1 & .006 & .660 & .492 & .886 \\
\hline & FIB4 (F0-F1) & .646 & .264 & 5.977 & 1 & .014 & 1.908 & 1.137 & 3.204 \\
\hline & Cirrhosis Discrimination Score (CDS) & -.166 & .077 & 4.596 & 1 & .032 & .847 & .728 & .986 \\
\hline & King's score & .009 & .004 & 5.491 & 1 & .019 & 1.009 & 1.002 & 1.017 \\
\hline
\end{tabular}

$p<0.05$ is significant.

Table 4

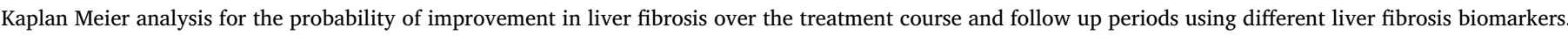

\begin{tabular}{|c|c|c|c|c|c|c|c|c|c|c|c|}
\hline \multirow{3}{*}{$\begin{array}{l}\text { Liver } \\
\text { Fibrosis } \\
\text { Biomarker }\end{array}$} & \multirow[t]{3}{*}{$\begin{array}{l}\text { Treatment } \\
\text { Response }\end{array}$} & \multirow[t]{3}{*}{$\begin{array}{l}\text { Case } \\
\text { summary }\end{array}$} & \multirow{3}{*}{$\begin{array}{l}\text { No of } \\
\text { Events n } \\
(\%)\end{array}$} & \multirow[t]{3}{*}{$\begin{array}{l}\text { Censored } \\
\text { n(\%) }\end{array}$} & \multirow{3}{*}{$\begin{array}{l}\text { Event } \\
\text { Time } \\
\text { (months) }\end{array}$} & \multirow{3}{*}{$\begin{array}{l}\text { No. of } \\
\text { Events } \\
\text { (recovery) }\end{array}$} & \multirow{3}{*}{$\begin{array}{l}\text { No. at Risk } \\
\text { (to } \\
\text { recovery) }\end{array}$} & \multirow[t]{3}{*}{$\begin{array}{l}\text { Probability of } \\
\text { recovering }\end{array}$} & \multicolumn{3}{|c|}{$\begin{array}{l}\text { Test of equality of recovery for levels of } \\
\text { treatment response }\end{array}$} \\
\hline & & & & & & & & & $\begin{array}{l}\text { Log Rank } \\
\text { (Mantel- } \\
\text { Cox) }\end{array}$ & $\begin{array}{l}\text { Breslow } \\
\text { (Generalized } \\
\text { Wilcoxon) }\end{array}$ & Tarone-Ware \\
\hline & & & & & & & & & $P$ value & & \\
\hline \multirow[t]{6}{*}{ APRI Score } & Responders & $\mathrm{n}=183$ & 174 & $9(4.9)$ & 1 & 87 & 96 & 0.475 & $<0.0001$ & .001 & $<0.0001$ \\
\hline & & & (95.1) & & 3 & 33 & 63 & 0.656 & & & \\
\hline & & & & & 6 & 54 & 9 & 0.951 & & & \\
\hline & Non- & $\mathrm{n}=4$ & $0(0.0)$ & $4(100.0)$ & 1 & 0 & 4 & 0.0 & & & \\
\hline & Responders & & & & 3 & 0 & 4 & 0.0 & & & \\
\hline & & & & & 6 & 0 & 4 & 0.0 & & & \\
\hline \multirow[t]{6}{*}{ Forns Index } & Responders & $\mathrm{n}=193$ & 116 & 77 (39.9) & 1 & 51 & 142 & 0.264 & .060 & .068 & .062 \\
\hline & & & $(60.1)$ & & 3 & 33 & 109 & 0.435 & & & \\
\hline & & & & & 6 & 32 & 77 & 0.601 & & & \\
\hline & Non- & $\mathrm{n}=4$ & $0(0.0)$ & $4(100.0)$ & 1 & 0 & 4 & 0.0 & & & \\
\hline & Responders & & & & 3 & 0 & 4 & 0.0 & & & \\
\hline & & & & & 6 & 0 & 4 & 0.0 & & & \\
\hline \multirow[t]{6}{*}{ FIB-4 } & Responders & $\mathrm{n}=192$ & 165 & $27(14.1)$ & 1 & 58 & 134 & 0.302 & .001 & .005 & .002 \\
\hline & & & $(85.6)$ & & 3 & 38 & 96 & 0.500 & & & \\
\hline & & & & & 6 & 69 & 27 & 0.859 & & & \\
\hline & Non- & $\mathrm{n}=4$ & $0(0.0)$ & $4(100.0)$ & 1 & 0 & 4 & 0.0 & & & \\
\hline & Responders & & & & 3 & 0 & 4 & 0.0 & & & \\
\hline & & & & & 6 & 0 & 4 & 0.0 & & & \\
\hline \multirow[t]{6}{*}{ mFIB-4 } & Responders & $\mathrm{n}=192$ & 107 & $85(44.3)$ & 1 & 13 & 179 & 0.068 & .131 & .138 & .134 \\
\hline & & & (55.7) & & 3 & 11 & 168 & 0.125 & & & \\
\hline & & & & & 6 & 83 & 85 & 0.557 & & & \\
\hline & Non- & $\mathrm{n}=4$ & $0(0.0)$ & $4(100.0)$ & 1 & 0 & 4 & 0.0 & & & \\
\hline & Responders & & & & 3 & 0 & 4 & 0.0 & & & \\
\hline & & & & & 6 & 0 & 4 & 0.0 & & & \\
\hline \multirow[t]{6}{*}{ Lok Index } & Responders & $\mathrm{n}=186$ & 100 & $86(46.2)$ & 1 & 11 & 175 & 0.059 & .057 & .063 & .060 \\
\hline & & & (53.8) & & 3 & 32 & 143 & 0.231 & & & \\
\hline & & & & & 6 & 57 & 86 & 0.538 & & & \\
\hline & Non- & $\mathrm{n}=4$ & $0(0.0)$ & $4(100.0)$ & 1 & 0 & 4 & 0.0 & & & \\
\hline & Responders & & & & 3 & 0 & 4 & 0.0 & & & \\
\hline & & & & & 6 & 0 & 4 & 0.0 & & & \\
\hline \multirow[t]{6}{*}{ GUCI } & Responders & $\mathrm{n}=195$ & 183 & $12(6.2)$ & 1 & 100 & 95 & 0.513 & $<0.0001$ & .001 & $<0.0001$ \\
\hline & & & $(93.8)$ & & 3 & 31 & 64 & 0.672 & & & \\
\hline & & & & & 6 & 52 & 12 & 0.938 & & & \\
\hline & Non- & $\mathrm{n}=4$ & $0(0.0)$ & $4(100.0)$ & 1 & 0 & 4 & 0.0 & & & \\
\hline & Responders & & & & 3 & 0 & 4 & 0.0 & & & \\
\hline & & & & & 6 & 0 & 4 & 0.0 & & & \\
\hline \multirow[t]{6}{*}{ King's Score } & Responders & $\mathrm{n}=193$ & 180 & $13(6.7)$ & 1 & 123 & 70 & 0.637 & $<0.0001$ & $<0.0001$ & $<0.0001$ \\
\hline & & & (93.3) & & 3 & 20 & 50 & 0.741 & & & \\
\hline & & & & & 6 & 37 & 13 & 0.933 & & & \\
\hline & Non- & $\mathrm{n}=4$ & $0(0.0)$ & $4(100.0)$ & 1 & 0 & 4 & 0.0 & & & \\
\hline & Responders & & & & 3 & 0 & 4 & 0.0 & & & \\
\hline & & & & & 6 & 0 & 4 & 0.0 & & & \\
\hline
\end{tabular}

$p<0.05$ is significant. 

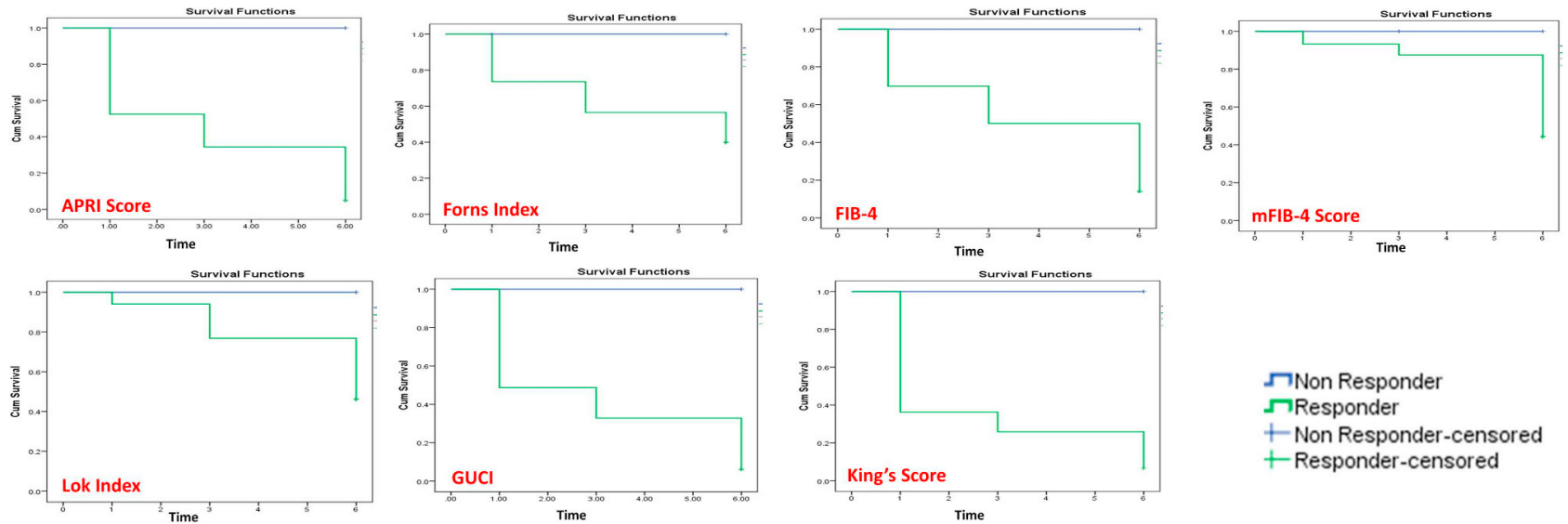

Fig. 4. The equality of recovery (improvement in liver fibrosis) over the treatment and follow-up periods among responders and non-responders.

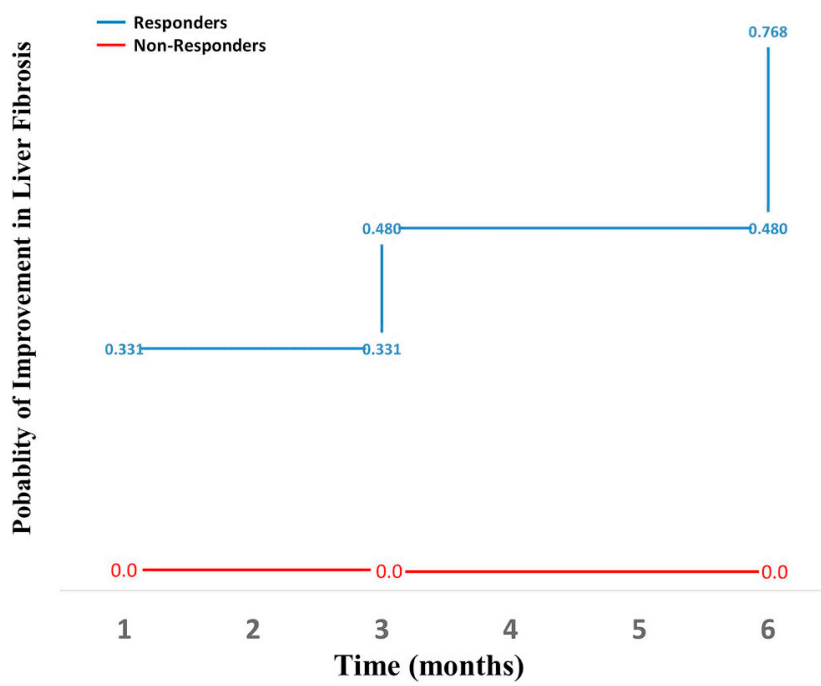

Fig. 5. The mean probability of recovery (improvement in liver fibrosis) over the treatment and follow-up periods among responders and non-responders.

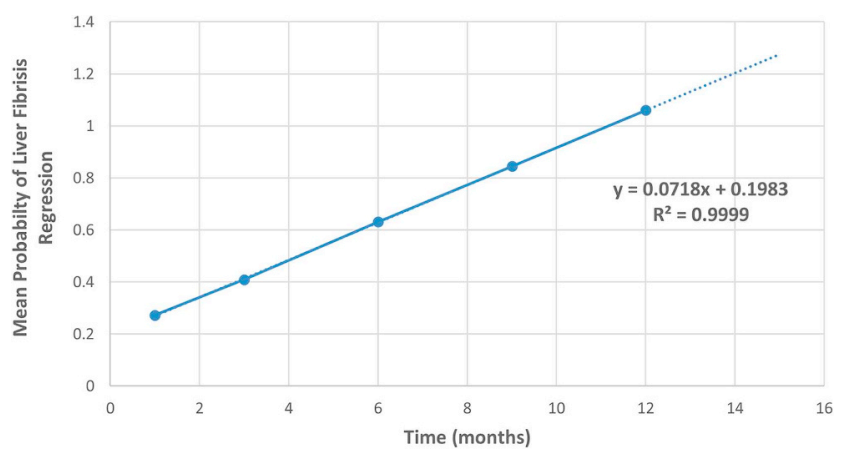

Fig. 6. Prediction of the continuous progressive regression in liver fibrosis overtime.

with fibrosis could be missed from the diagnosis which is an important factor affecting the efficacy of chronic hepatitis treatment. ${ }^{39}$ Fibrosis can be detected and staged with reasonable accuracy using TE and ARFI. These have high sensitivities and specificities to diagnosis from significant fibrosis to liver cirrhosis and can be used to predict prognosis. ${ }^{56,57}$ However, when the performance of NIBMs was compared to TE, ARFI or liver biopsy, comparable sensitivity and specificity values to our study results were obtained. Moreover, NIBMs are less accurate in detecting intermediate stages of fibrosis than cirrhosis with a mean standardized AUROC for diagnosis of fibrosis/cirrhosis of 0.76-0.89 and the sensitivities and specificities ranged between 50 and $90 \% .^{8,10,13,58-65}$

Resolution of established liver fibrosis might take several years to occur. ${ }^{66,67}$ Earlier findings from animal models of chronic liver disease alongside a growing evidence from clinical studies evaluated early changes in dynamic fibrosis-related parameters during DAA based therapy using the enhanced liver fibrosis (ELF) panel, combined with liver stiffness measurement. ${ }^{31,68-70}$ In the present real-life cohort, we employed the use of some NIBMs for liver fibrosis which showed significant reduction reaching $>90 \%(53.8-95.1 \%) 12$ weeks after EOT compared to baseline values. These scores are affected by the increased platelets count as well as the reduction of AST, ALT, and yGT levels. Sustained responders in the present cohort showed significant reduction in these scores comparing to relapsers denoting improvement in necroinflammation and liver fibrosis after successful DAAs based antiviral therapy. Early studies comparing INF based regimens reported a $62 \%$ improvement in liver fibrosis after achieving SVR in paired liver biopsies. ${ }^{58}$ In fact, improvement of liver stiffness measurements occurs by the EOT regardless the treatment outcome which can reflect the temporary reduction in viral replication. This remains controversial as this early changes may represent an actual improvement in liver fibrosis or a result of resolved necroinflammatory activity following antiviral treatment. However, other studies stated that the inflammatory activity did not contribute to liver stiffness. ${ }^{68,71}$ The median of the liver stiffness measurement was observed to decrease by more than $60 \%$ of pretreatment values in patients with advanced fibrosis or cirrhosis. ${ }^{72}$ Various studies reported different degrees of improvement in liver fibrosis as assessed by different modalities and the median time for improvement (Table 5).

With the previously used INF and ribavirin, several studies reported factors associated with decline in liver stiffness measurements after antiviral therapy as baseline fibrosis stage, baseline activity, SVR, BMI, age, and viral load. ${ }^{67}$ With the recent use of DAAs, this issue is still under research. However it seems that age, viral load, BMI, and baseline activity will no longer have a role. In the present study, normal baseline ALT, AST, TSC, serum albumin, WBCS, prothrombin activity and early stages of liver fibrosis as revealed by liver fibrosis scoring (FIB-4, Forns, and CDS) predicted improvement in liver fibrosis by 1.5-2 folds.

SVR has an established role in improvement in liver fibrosis status. ${ }^{73}$ Poynard et al. identified in a multivariate logistic regression analysis factors other than SVR that were associated with likely fibrosis regression/reversal after treatment. These included younger age, low BMI, higher platelet count, absence of portal hypertension and mild virus activity, supporting a better chance for early cirrhosis to regress 
than established cirrhosis. ${ }^{17}$

The presence of co-morbidities, hepatic steatosis or risky behaviors such as smoking and alcohol consumption are likely determinants to limit liver fibrosis regression in sustained responders ${ }^{67}$ although this was not evident in the present study. Such analysis of underlying risk factors would be helpful during the follow-up of SVR patients to exclude potential post-SVR HCV specific mechanisms that account for fibrosis progression.

HCV can alter glucose metabolism leading to insulin resistance ${ }^{74}$ which has a strong influence on $\mathrm{SVR}^{75,76}$ and accelerated fibrogenesis. ${ }^{77,78}$ This comes in line with the current study, as the FBG, PPBG and HbA1Cshowed linear improvement over the course of DAAs treatment and during the 3 months of follow up.

The employed extrapolation forecasting test in the present cohort predicted continuous progressive regression in liver fibrosis over time. Prior studies showed that fibrosis markers and liver histology improves significantly post-SVR. ${ }^{79,80}$ On the other hand, Chekuri et al., found that minimal further reduction in liver-stiffness can occur in the interval from SVR24 to the end of follow-up, suggesting that fibrosis regresses slowly after achieving SVR when it regresses at all. ${ }^{31}$

Treatment regimens for HCV are rapidly changing, and there is a great need for further studies on the effect of each regimen on liver fibrosis. Fibrosis regression has been shown to decrease the risk of HCC and mortality, ${ }^{81}$ but many patients are offered HCV treatment after fibrosis has been established. Since in the present study fibrosis was found in many patients, early diagnosis and treatment before advanced fibrosis and permanent liver damage has been established is warranted to maximize the benefits from antiviral treatment.

Collectively, the rapid improvements in HCV therapies will greatly enhance the likelihood of SVR among all patient groups with HCV infection, including those traditionally considered 'hard to treat'. Sofosbuvir-based therapy causes a clinically significant improvement in hepatic fibrosis as measured non-invasive liver fibrosis biomarkers even in cirrhotic patients. Our results indicate that non-invasive fibrosis scores were fairly accurate noninvasive blood tests to predict the presence or absence of significant fibrosis. This enabled us to provide prognostic data regarding the improvement in liver fibrosis over the treatment course and follow up periods without the need for a liver biopsy. Nevertheless, adequate follow-up is warranted to evaluate impact of SVR on fibrosis since the impact of HCV infection could stay many years and result in advanced liver diseases.

\subsection{Limitation of the study}

Both direct and indirect variables are utilized to possibly predict liver fibrosis. However, all have limitations in accuracy indices as a perfect test. Accordingly, indirect NIBMs are crude indices to reflect real changes in liver fibrosis. Most of these indices relay on necro-inflammatory markers which obviously improve much with eradication of the virus. Thus, the decreased values of these NIBMs are reflecting improvement in the necro-inflammatory state rather than a real regression of liver fibrosis which may occur simultaneously but at a different rate. Moreover, the follow up duration was too short to infer a change in liver fibrosis state.

\section{Research involving human participants/or animals}

The study was approved by the institutional review board and the ethics committee of the High Institute of Public Health affiliated to Alexandria University, Egypt. The research was conducted in accordance with the international ethical guidelines of the Declaration of Helsinki (2013) and the International Conference on Harmonization Guidelines for Good Clinical Practice. Data sheets were coded to ensure anonymity and confidentiality of patient's data. This article does not contain any studies with animals performed by any of the authors. 


\section{Informed consent}

Informed written consent was obtained from all individual participants enrolled after explaining the aim and concerns of the study.

\section{Availability of data}

All data are fully available without restriction.

\section{Declaretion Conflict of interest}

None to Declare.

\section{Acknowledgement}

We would like to thank the study participants for accepting to participate in the study.

\section{Appendix A. Supplementary data}

Supplementary data to this article can be found online at https:// doi.org/10.1016/j.cegh.2020.04.011.

\section{References}

1. Singal AG, Volk ML, Jensen D, et al. A sustained viral response is associated with reduced liver-related morbidity and mortality in patients with hepatitis $\mathrm{C}$ virus. Clin Gastroenterol Hepatol. 2010;8:280-288 288 e1.

2. Arima Y, Kawabe N, Hashimoto S, et al. Reduction of liver stiffness by interferon treatment in the patients with chronic hepatitis C. Hepatol Res. 2010;40:383-392.

3. Pearlman BL, Traub N. Sustained virologic response to antiviral therapy for chronic hepatitis C virus infection: a cure and so much more. Clin Infect Dis. 2011;52:889-900

4. Regev A, Berho M, Jeffers LJ, et al. Sampling error and intraobserver variation in liver biopsy in patients with chronic HCV infection. Am J Gastroenterol 2002; $97: 2614-2618$.

5. Ratziu V, Charlotte F, Heurtier A, et al. Sampling variability of liver biopsy in nonalcoholic fatty liver disease. Gastroenterology. 2005;128:1898-1906.

6. Poynard T, Ratziu V, Bedossa P. Appropriateness of liver biopsy. Can J Gastroenterol. 2000;14:543-548.

7. Patel K, Nelson DR, Rockey DC, et al. Correlation of FIBROSpect II with histologic and morphometric evaluation of liver fibrosis in chronic hepatitis C. Clin Gastroenterol Hepatol. 2008;6:242-247.

8. Schiavon Lde L, Narciso-Schiavon JL, de Carvalho-Filho RJ. Non-invasive diagnosi of liver fibrosis in chronic hepatitis C. World J Gastroenterol. 2014;20:2854-2866.

9. Castera L, Pinzani M. Biopsy and non-invasive methods for the diagnosis of liver fibrosis: does it take two to tango? Gut. 2010;59:861-866.

10. Baranova A, Lal P, Birerdinc A, et al. Non-invasive markers for hepatic fibrosis. BMC Gastroenterol. 2011;11:91.

11. Jarcuska P, Janicko M, Veseliny E, et al. Circulating markers of liver fibrosis progression. Clin Chim Acta. 2010;411:1009-1017.

12. Castera L. Invasive and non-invasive methods for the assessment of fibrosis and disease progression in chronic liver disease. Best Pract Res Clin Gastroenterol. 2011;25:291-303.

13. Tatsumi C, Kudo M, Ueshima K, et al. Noninvasive evaluation of hepatic fibrosis using serum fibrotic markers, transient elastography (FibroScan) and real-time tissue elastography. Intervirology. 2008;51(Suppl 1):27-33.

14. El Serafy MA, Kassem AM, Omar H, et al. APRI test and hyaluronic acid as noninvasive diagnostic tools for post HCV liver fibrosis: systematic review and metaanalysis. Arab Journal of Gastroenterology. 2017;18:51-57.

15. Coverdale SA, Khan MH, Byth K, et al. Effects of interferon treatment response on liver complications of chronic hepatitis C: 9-year follow-up study. Am J Gastroenterol 2004;99:636-644

16. Veldt BJ, Heathcote EJ, Wedemeyer H, et al. Sustained virologic response and clinical outcomes in patients with chronic hepatitis $\mathrm{C}$ and advanced fibrosis. Ann Intern Med. 2007;147:677-684.

17. Poynard T, McHutchison J, Manns M, et al. Impact of pegylated interferon alfa-2b and ribavirin on liver fibrosis in patients with chronic hepatitis C. Gastroenterology 2002;122:1303-1313

18. Camma C, Di Bona D, Schepis F, et al. Effect of peginterferon alfa-2a on liver histology in chronic hepatitis C: a meta-analysis of individual patient data. Hepatology. 2004;39:333-342.

19. Li G, De Clercq E. Current therapy for chronic hepatitis C: the role of direct-acting antivirals. Antivir Res. 2017;142:83-122.

20. Ministry of Health and Population. Guidelines for Treatment of HCV. National Committee for Control of Viral Hepatitis; 2015

21. EASL. EASL recommendations on treatment of hepatitis C 2018. J Hepatol 2018;69:461-511
22. AASLD-IDSA. Hepatitis C guidance 2018 update: AASLD-IDSA recommendations for testing, managing, and treating hepatitis C virus infection. Clin Infect Dis. 2018;67:1477-1492.

23. Li Y, Chen Y, Zhao Y. The diagnostic value of the FIB-4 index for staging hepatitis Brelated fibrosis: a meta-analysis. PloS One. 2014;9:e105728.

24. Salama H, Zekri A, Medhat E, et al. Effect of sofosbuvir, brand drug (Sovaldi) versus generic (MPI Viropack) in treating chronic HCV genotype 4 infection among Egyptian patients. EC Gastroenterology and Digestive System. 2016;1.

25. Fouad R, Hashem MB, Elsharkawy A, et al. High SVR4 in the treatment of chronic HCV genotype 4 patients with sofosbuvir and daclatasvir (both generic). EASLAASLD Special Conference: New Perspectives in Hepatitis C Virus Infection - the Roadmap for Cure. Paris. Springer Berlin Heidelberg; 2016

26. Ray SC, Arthur RR, Carella A, et al. Genetic epidemiology of hepatitis C virus throughout Egypt. J Infect Dis. 2000;182:698-707.

27. Eslam M, Aparcero R, Kawaguchi T, et al. Meta-analysis: insulin resistance and sustained virological response in hepatitis C. Aliment Pharmacol Ther. 2011;34:297-305

28. Guerra J, Garenne M, Mohamed MK, et al. HCV burden of infection in Egypt: results from a nationwide survey. J Viral Hepat. 2012;19:560-567.

29. Bruggmann P, Berg T, Ovrehus AL, et al. Historical epidemiology of hepatitis C virus (HCV) in selected countries. J Viral Hepat. 2014;21(Suppl 1):5-33.

30. Landis JR, Koch GG. The measurement of observer agreement for categorical data. Biometrics. 1977;33:159-174.

31. Chekuri S, Nickerson J, Bichoupan K, et al. Liver stiffness decreases rapidly in response to successful hepatitis C treatment and then plateaus. PloS One 2016;11:e0159413.

32. Kim JH, Kim MN, Han KH, et al. Clinical application of transient elastography in patients with chronic viral hepatitis receiving antiviral treatment. Liver Int. 2015;35:1103-1115

33. Marcellin P, Boyer N, Gervais A, et al. Long-term histologic improvement and loss of detectable intrahepatic HCV RNA in patients with chronic hepatitis C and sustained response to interferon-alpha therapy. Ann Intern Med. 1997;127:875-881.

34. Akhtar E, Manne V, Saab S. Cirrhosis regression in hepatitis C patients with sustained virological response after antiviral therapy: a meta-analysis. Liver Int. 2015;35:30-36.

35. Elsharkawy A, Alem SA, Fouad R, et al. Changes in liver stiffness measurements and fibrosis scores following sofosbuvir based treatment regimens without interferon. $J$ Gastroenterol Hepatol. 2017;32:1624-1630.

36. Abd El-Wahab EW, Mikheal A, Sidkey F, et al. Factors associated with hepatitis C infection among chronic HCV Egyptian patients. Iran J Public Health 2014:43:1510-1518.

37. El-Zanaty F, Way A. Egypt Health Issue Survey 2015. Cairo: Egyptian Ministry of Health and Population; El-Zanaty and Associates and Macro International; 2015.

38. WHO. Chronic disease: fact sheet. Available at: https://www who.int/topics/ chronic diseases/factsheets/en/; 2013.

39. Choong CC, Venkatesh SK, Siew EP. Accuracy of routine clinical ultrasound for staging of liver fibrosis. J Clin Imaging Sci. 2012;2:58.

40. Lin YS. Ultrasound evaluation of liver fibrosis. J Med Ultrasound. 2017:25:127-129.

41. Ahmed MH, Noor SK, Bushara SO, et al. Non-alcoholic fatty liver disease in Africa and Middle East: an attempt to predict the present and future implications on the healthcare system. Gastroenterol Res. 2017;10:271-279.

42. Borai IH, Shaker Y, Kamal MM, et al. Evaluation of biomarkers in Egyptian patients with different grades of nonalcoholic fatty liver disease. J Clin Transl Hepatol. 2017;5:109-118

43. Huber A, Ebner L, Heverhagen JT, et al. State-of-the-art imaging of liver fibrosis and cirrhosis: a comprehensive review of current applications and future perspectives. Eur J Radiol Open. 2015;2:90-100.

44. Bohte AE de Niet A, Jansen $\mathrm{L}$, et al Non-invasive evaluation of liver fibrosis: a comparison of ultrasound-based transient elastography and MR elastography in patients with viral hepatitis B and C. Eur Radiol. 2014;24:638-648.

45. Omar H, El Akel W, Elbaz T, et al. Generic daclatasvir plus sofosbuvir, with or without ribavirin, in treatment of chronic hepatitis C: real-world results from 18378 patients in Egypt. Aliment Pharmacol Ther. 2018;47:421-431.

46. Nagaty A, Abd El-Wahab EW. Real-life results of sofosbuvir based therapy in chronic hepatitis C -naive and -experienced patients in Egypt. PloS One. 2017;12:e0184654.

47. Sherigar JM, Gayam V, Khan A, et al. Clinical efficacy and tolerability of directacting antivirals in elderly patients with chronic hepatitis C. Eur J Gastroenterol Hepatol. 2017;29:767-776.

48. Rehman S. Safety, tolerability, and associated side effects of direct- acting antivirals, hepatitis C. Available at: https://www.intechopen.com/books/hepatitis-c-frominfection-to-cure/safety-tolerability-and-associated-side-effects-of-direct-actingantivirals; 2018

49. Elsharkawy A, Fouad R, El Akel W, et al. Sofosbuvir-based treatment regimens: rea life results of 14409 chronic HCV genotype 4 patients in Egypt. Aliment Pharmacol Ther. 2017;45:681-687.

50. Abd El-Wahab EW, Mikheal A, Sidkey F, et al. Insulin resistance as a predictor of early virologic response to HCV therapy among chronic HCV Egyptian patients. $J$ Med Virol. 2015;87:428-440.

51. Desbois AC, Cacoub P. Diabetes mellitus, insulin resistance and hepatitis C virus infection: a contemporary review. World J Gastroenterol. 2017;23:1697-1711.

52. Khattab M, Emad M, Abdelaleem A, et al. Pioglitazone improves virological response to peginterferon alpha-2b/ribavirin combination therapy in hepatitis $\mathrm{C}$ genotype 4 patients with insulin resistance. Liver Int. 2010;30:447-454

53. Backus LI, Belperio PS, Shahoumian TA, et al. Effectiveness of sofosbuvir-based regimens in genotype 1 and 2 hepatitis $\mathrm{C}$ virus infection in 4026 U.S. Veterans. Aliment Pharmacol Ther. 2015;42:559-573. 
54. Butt AA, Yan P, Shaikh OS, et al. Treatment adherence and virologic response rates in HCV infected persons treated with sofosbuvir-based regimens: results from ERCHIVES. Liver Int. 2016;36(9):1275-1283.

55. Romero-Gomez M. Insulin resistance and hepatitis C. World J Gastroenterol. 2006;12:7075-7080.

56. Gerstenmaier JF, Gibson RN. Ultrasound in chronic liver disease. Insights Imaging. 2014;5:441-455

57. Piscaglia F, Marinelli S, Bota S, et al. The role of ultrasound elastographic techniques in chronic liver disease: current status and future perspectives. Eur J Radiol 2014;83:450-455.

58. EASL. EASL-ALEH clinical practice guidelines: non-invasive tests for evaluation of liver disease severity and prognosis. J Hepatol. 2015;63:237-264.

59. Amorim TG, Staub GJ, Lazzarotto C, et al. Validation and comparison of simple noninvasive models for the prediction of liver fibrosis in chronic hepatitis C. Ann Hepatol. 2012;11:855-861.

60. Boursier J, de Ledinghen V, Zarski JP, et al. Comparison of eight diagnostic algorithms for liver fibrosis in hepatitis C: new algorithms are more precise and entirely noninvasive. Hepatology. 2012;55:58-67.

61. Castera L, Sebastiani G, Le Bail B, et al. Prospective comparison of two algorithms combining non-invasive methods for staging liver fibrosis in chronic hepatitis C. $J$ Hepatol. 2010;52:191-198.

62. Catanzaro R, Milazzo M, Arona S, et al. Diagnostic accuracy of enhanced liver fibrosis test to assess liver fibrosis in patients with chronic hepatitis C. Hepatobiliary Pancreat Dis Int. 2013;12:500-507.

63. Fernandes FF, Ferraz ML, Andrade LE, et al. Enhanced liver fibrosis panel as a predictor of liver fibrosis in chronic hepatitis C patients. $J$ Clin Gastroenterol 2015;49:235-241.

64. Gokcan H, Kuzu UB, Oztas E, et al. The predictive value of noninvasive serum markers of liver fibrosis in patients with chronic hepatitis C. Turk $J$ Gastroenterol. 2016;27:156-164.

65. Vallet-Pichard A, Mallet V, Nalpas B, et al. FIB-4: an inexpensive and accurate marker of fibrosis in HCV infection. comparison with liver biopsy and fibrotest. Hepatology. 2007; 46:32-36.

66. Ellis EL, Mann DA. Clinical evidence for the regression of liver fibrosis. J Hepatol 2012;56:1171-1180.

67. Dumortier J, Leroy V, Duvoux C, et al. Sofosbuvir-based treatment of hepatitis C with severe fibrosis (METAVIR F3/F4) after liver transplantation: results from the CO23 ANRS CUPILT study. Liver Transplant. 2016;17(11):2869-2878.

68. Hezode C, Castera L, Roudot-Thoraval F, et al. Liver stiffness diminishes with antiviral response in chronic hepatitis C. Aliment Pharmacol Ther. 2011;34:656-663.

69. Lee YA, Friedman SL. Reversal, maintenance or progression: what happens to the liver after a virologic cure of hepatitis C? Antivir Res. 2014;107:23-30.

70. Bernuth S, Yagmur E, Schuppan D, et al. Early changes in dynamic biomarkers of liver fibrosis in hepatitis C virus-infected patients treated with sofosbuvir. Dig Liver Dis. 2016;48:291-297.

71. Coco B, Oliveri F, Maina AM, et al. Transient elastography: a new surrogate marker of liver fibrosis influenced by major changes of transaminases. $J$ Viral Hepat. 2007; 14:360-369.

72. Karlas T, Benckert J, Beer S, et al. Letter: can persisting liver stiffness indicate increased risk of HCC, after successful anti-HCV therapy? Aliment Pharmacol Ther. 2016;43:543-544.

73. Dolmazashvili E, Abutidze A, Chkhartishvili N, et al. Regression of liver fibrosis over a 24-week period after completing direct-acting antiviral therapy in patients with chronic hepatitis $\mathrm{C}$ receiving care within the national hepatitis $\mathrm{C}$ elimination program in Georgia: results of hepatology clinic HEPA experience. Eur J Gastroenterol Hepatol. 2017;29:1223-1230.

74. Negro F. Steatosis and insulin resistance in response to treatment of chronic hepatitis C. J Viral Hepat. 2012;19(Suppl 1):42-47.

75. Poustchi H, Negro F, Hui J, et al. Insulin resistance and response to therapy in patients infected with chronic hepatitis C virus genotypes 2 and 3. J Hepatol. 2008;48:28-34.

76. Chu CJ, Lee SD, Hung TH, et al. Insulin resistance is a major determinant of sustained virological response in genotype 1 chronic hepatitis $\mathrm{C}$ patients receiving peginterferon alpha-2b plus ribavirin. Aliment Pharmacol Ther. 2009;29:46-54.

77. Moucari R, Asselah T, Cazals-Hatem D, et al. Insulin resistance in chronic hepatitis C: association with genotypes 1 and 4, serum HCV RNA level, and liver fibrosis. Gastroenterology. 2008;134:416-423.

78. Petta S, Camma C, Di Marco V, et al. Insulin resistance and diabetes increase fibrosis in the liver of patients with genotype $1 \mathrm{HCV}$ infection. Am J Gastroenterol. 2008;103:1136-1144.

79. Shiratori Y, Imazeki F, Moriyama M, et al. Histologic improvement of fibrosis in patients with hepatitis $\mathrm{C}$ who have sustained response to interferon therapy. Ann Intern Med. 2000;132:517-524.

80. Fontana RJ, Bonkovsky HL, Naishadham D, et al. Serum fibrosis marker levels decrease after successful antiviral treatment in chronic hepatitis C patients with advanced fibrosis. Clin Gastroenterol Hepatol. 2009;7:219-226.

81. Casado JL, Esteban MA, Banon S, et al. Fibrosis regression explains differences in outcome in HIV-/HCV-coinfected patients with cirrhosis after sustained virological response. Dig Dis Sci. 2015;60:3473-3481.

82. Poynard T, Moussalli J, Munteanu M, et al. Slow regression of liver fibrosis presumed by repeated biomarkers after virological cure in patients with chronic hepatitis C. $J$ Hepatology. 2013;59(4):675-683. https://doi.org/10.1016/j.jhep.2013.05.015 S0168-8278(13)00345-0 [pii].

83. Crissien-Martinez A, Minteer W, Frenette C, et al. Regression of advanced fibrosis or cirrhosis measured by elastography in patients with chronic hepatitis $\mathrm{C}$ who achieve sustained virologic response after treatment for HCV. Hepatology. 2015;62(S1):108.

84. Bruno G, Dell'Acqua E, Milano E, et al. Early regression of liver fibrosis in HCV infected patients with or without HIV infection after treatment with DAAs. Hepatology. 2016;64:326A.

85. Bachofner JA, Valli PV, Kroger A, et al. Direct antiviral agent treatment of chronic hepatitis $C$ results in rapid regression of transient elastography and fibrosis markers fibrosis-4 score and aspartate aminotransferase-platelet ratio index. Liver Int. 2017;37(3):369-376. https://doi.org/10.1111/liv.13256.

86. Mehrez MI, Saleh MA, Fareid A. Fibrosis tegression after treatment with DAAs. Gastroenterology \& Hepatology: Open Access. 2017;7(1):e00223.

87. Singh S, Facciorusso A, Loomba R, et al. Magnitude and kinetics of decrease in liver stiffness after antiviral therapy in patients with chronic hepatitis C: a systematic review and meta-analysis. Clin Gastroenterol Hepatol. 2018;16(1):27-38.

88. Rayes J, Sebastiani G. A190 regression of liver fibrosis after successful all oral antiviral therapy in HCV cirrhosis: a pilot study employing transient elastography and controlled attenuation parameter (CAP). J Can Assoc Gastroenter. 2018;1(1):331.

89. Pan JJ, Bao F, Du E, et al. Morphometry confirms fibrosis regression from sustained virologic response to direct-acting antivirals for hepatitis C. Hepatol Commun. 2018;2(11):1320-1330. https://doi.org/10.1002/hep4.1228 HEP41228 [pii]. 